\title{
Coral Recruit-Algae Interactions in Coral Reef Lagoons Are Mediated by Riverine Influences
}

\author{
S. A. Mwachireya, A. M. Nzioka, and D. N. Mutiso \\ Department of Oceanography and Hydrography, Kenya Marine and Fisheries Research Institute, Silos Rd., \\ English Point, Mkomani, P.O. Box 81651, Mombasa 80100, Kenya
}

Correspondence should be addressed to S. A. Mwachireya; mwachireya@yahoo.com

Received 18 January 2017; Revised 31 May 2017; Accepted 1 June 2017; Published 9 July 2017

Academic Editor: Daniel I. Rubenstein

Copyright (C) 2017 S. A. Mwachireya et al. This is an open access article distributed under the Creative Commons Attribution License, which permits unrestricted use, distribution, and reproduction in any medium, provided the original work is properly cited.

\begin{abstract}
Coral recruit and algae abundance and diversity were studied in Kenyan reefs to determine the influence of terrestrial discharge (nutrients and sediments) and the recovery potential of coral reefs after disturbances. Reefs affected by sediments and nutrients were found to have high total, turf, and macroalgae but reduced coralline algae abundance and coral recruit density. Interestingly, this response was found to be the greatest in reefs close to nutrient sources relative to "pristine" reefs and those affected simultaneously by sediments and nutrients. Further, enhanced levels of brown algae and pocilloporid recruits were observed in reefs affected by terrestrial run-off whereas acroporid recruit, coralline, and calcareous algae abundance was high in reefs under low terrestrial input. Our results show that whereas increased sediment levels negatively affect coral recruit density individually, their interaction with nutrients improves recruit density in reefs simultaneously affected by sediment and nutrients. These findings suggest that the assessment of local factors that enhance inhibitory and those that suppress promotional processes involved in coral settlement and recruitment is an important aspect to consider in the conservation and management of coral reefs in the face of local anthropogenic stress as well as future climate disturbance dynamics and their interaction.
\end{abstract}

\section{Introduction}

Coral reefs are among the most diverse and productive marine ecosystems on the planet directly providing food, protection, and income to many coastal and island inhabitants. However, over the past few decades, coral reefs globally have experienced increased stress from a combination of natural and anthropogenic pressures. Reefs continue to be adversely affected by disturbances such as climate change, destructive fishing, and overharvesting as well as land and marinebased pollution [1-4]. Disturbances such as sediment influx, overfishing, and organic and inorganic pollution have been linked to local ecological modifications in reefs worldwide [5-7] with severe consequences on coral reef communities, processes [7-12], and the socioeconomics of coastal communities. Presently, countering the effects of these stressors poses the greatest challenge in coral conservation and management. The adoption and implementation of scientifically based solutions and strategies for protection and conservation of coral reefs are likely to improve the efficacy and efficiency of contemporary intervention protocols.

Poor land use and coastal development activities increase sediment and nutrient discharge into coastal and marine areas adversely affecting early and adult life stages of marine biota [6, 13-21]. For instance, terrestrial run-off has been reported to negatively impact important ecological processes [20-24] responsible for the replenishment of populations in disturbed reefs. Studies [17, 23, 24] have indicated that the recovery of such reefs is principally determined by local environmental factor dynamics, habitat conditions and characteristics, and the success of early coral growth phases (regrowth of coral fragments or settlement, growth, and mortality). Algal dominance in many degraded reef areas has become a major concern worldwide due to its negative impact on coral settlement and reef resilience. Moreover, predicted climate change events [25] and coral diseases [26] are expected to potentially enhance more algal colonization and reduce the reproductive capacity of coral populations 
[27-29] further interfering with coral settlement, coral reef ecological processes, and recovery potential.

In coral reefs, a few ecological processes have been found to exhibit large disproportionate impacts on community composition, structure, and functioning of reef ecosystems. One such process in benthic reef communities and dynamics is competition between corals and algae. A number of studies have shown corals to be inferior competitors relative to algae [30, 31]; however, other authors have found corals to be the superior competitors, only releasing algae from competitive inhibition under stressful conditions [4, 32], such as land-based (terrestrial) discharge. Modification of algal-coral competition by disturbances of terrestrial origin may thus play a crucial role in mediating optimal habitat characteristics, diversity, resilience, and recovery potential of disturbed reefs [33-37]. Herbivorous fishes regulate algal growth on coral reefs and are important for maintaining resilient, coral-dominated ecosystems. Increased sediment levels directly affect ecological processes and significantly reduce/inhibit feeding rates of herbivorous and detritivorous fish species [12-14]. Consequently, algal development [16] and dominance are enhanced with direct negative effects on coral settlement [15], benthic communities, and reef recovery potential $[12-15,22,23]$. This problem may be exacerbated in highly exploited reefs by the removal of grazing and browsing fish populations $[16,20,30,38]$.

Earlier studies on the effects of high algal biomass and sediment levels on coral settlement, survival, and diversity $[15,16,32,39,40]$ have provided interesting results. High sediment levels have been found to have both inductive and inhibitive cues for planktonic larval settlement [41, 42]. For example, increased sedimentation has been found to reduce [15], enhance [6], or even have no effect on coral larval settlement [38]. Similarly, the effects of sediments on benthic algae have not been found to be categorical either, with both positive and negative effects (low as well as high algal abundance) being associated with elevated sediment levels $[6,16,37,43-45]$. Additionally, observed variations in the response of different algae types to terrestrial run-off imply equally variable coral-algae competition outcomes [17]. Moreover, sediment characteristics and quality have also been observed to modify herbivory intensity with consequences on the growth and biomass of algae $[12,13,16,30]$ and, therefore, coral settlement and recruitment. The foregoing findings therefore suggest that the outcome and general importance of coral-algae competition may be much more complex than previously understood. Assessment of the different mechanisms and factors determining the outcomes of algae-coral interactions, more so during the early life stages of corals, is thus critically important for improved reef management, especially with the continuing harvest of reef herbivores and the increased frequency and severity of local and global anthropogenic disturbances.

This has important coral reef conservation/management implications and application in the face of changes occasioned by the interaction between local and global climate change as well as forecasting the resilience and capacity of corals to resist or recover from disturbances. Here, we report on the effect of elevated terrestrial discharge on algal

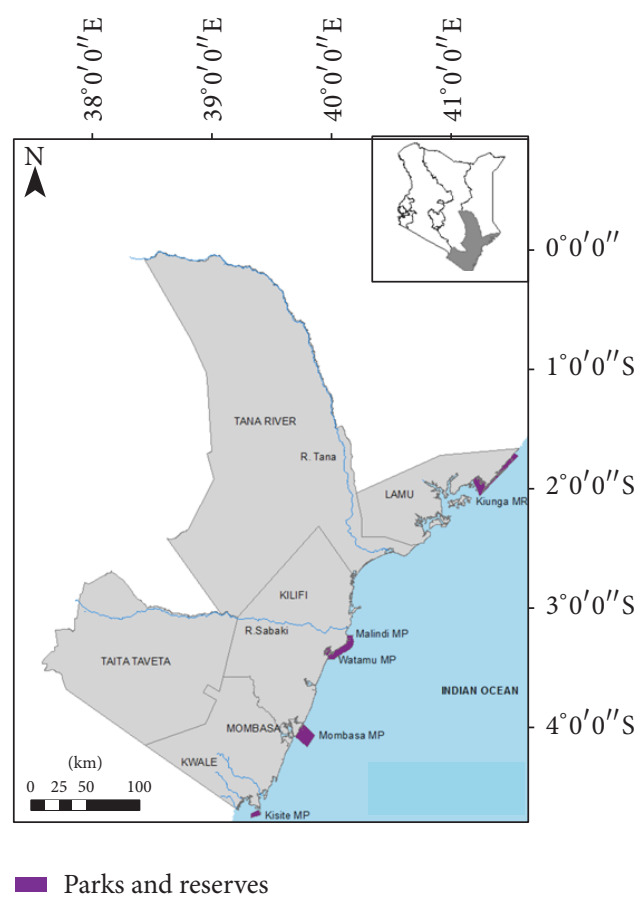

FIGURE 1: Map of the Kenyan coast showing the four studied marine protected areas (MPAs): Malindi, Watamu, Mombasa, and Shimoni (Kisite/Mpunguti).

abundance and diversity and the consequent impact on coral recruit composition and settlement in Kenyan coral reef lagoons.

\section{Materials and Methods}

2.1. Study Sites. Four fully protected reefs, Malindi, near the mouth of River Sabaki and under river influence during the northeast monsoon season (nutrient and sediment laden freshwater), two mangrove-fringed reefs (Watamu and Mombasa), and an offshore reef (Shimoni) were chosen for this study (Figure 1). Watamu reef lies adjacent to the $360 \mathrm{~km}^{2}$ Mida mangrove creek while Mombasa is a lagoonal fringing reef that experiences occasional water exchange with two creeks (Tudor and Mtwapa) on either side of the reef. All four reefs have had protection from fishing and shell collection for over 15 years now and are fully described in [6].

2.2. Physicochemical and Biological Parameters. Temperature and salinity measurements were taken monthly using an automatic probe and current velocity with a modified current drogue. Chlorophyll $a$, phosphate, and nitrate concentrations were determined spectrophotometrically after water filtration of triplicate $1 \mathrm{~L}$ samples through $0.45 \mu \mathrm{m}$ glass filters. Nitrates were first reduced to nitrites by passing samples through a column containing copper coated cadmium fillings followed by diazotization with sulfanilamide and coupling with $\mathrm{N}$-(1naphthyl)ethylenediamine. Phosphate samples were reacted with a composite reagent containing molybdic acid, ascorbic acid, and trivalent antimony. The absorbance of the resultant 
TABLE 1: Environmental parameters measured for each reef from the study with significant levels indicated by $*<0.05$ and ns $=$ nonsignificant.

${ }^{1}$ Trapped (deposited sediments) collected from sediment traps.

\begin{tabular}{|c|c|c|c|c|c|c|}
\hline Parameter & Malindi & Watamu & Mombasa & Shimoni & $F$ & $p$ \\
\hline Current $\left(\mathrm{m} \mathrm{s}^{-1}\right)$ & $0.3 \pm 0.0$ & $0.2 \pm 0.0$ & $0.2 \pm 0.0$ & $0.2 \pm 0.0$ & 1.86 & $*$ \\
\hline Chlorophyll $a\left(\mu \mathrm{g} \mathrm{l}^{-1}\right)$ & $0.6 \pm 0.2$ & $0.7 \pm 0.2$ & $0.3 \pm 0.3$ & $0.4 \pm 0.3$ & 4.13 & * \\
\hline Nitrates $\left(\mathrm{mg} \mathrm{l}^{-1}\right)$ & $1.5 \pm 0.5$ & $1.2 \pm 0.3$ & $0.9 \pm 0.4$ & $0.8 \pm 0.4$ & 2.35 & * \\
\hline Phosphates $\left(\mathrm{mg} \mathrm{l}^{-1}\right)$ & $1.0 \pm 0.1$ & $0.8 \pm 0.1$ & $0.8 \pm 0.1$ & $0.7 \pm 0.1$ & 0.44 & ns \\
\hline TSS $\left(\mathrm{g} \mathrm{l}^{-1}\right)$ & $28.5 \pm 4.8$ & $28.1 \pm 4.3$ & $23.9 \pm 1.1$ & $21.5 \pm 0.6$ & 7.00 & * \\
\hline Trapped $^{1}\left(\mathrm{~g} \mathrm{~m}^{-2}\right.$ day $\left.^{-1}\right)$ & $10.1 \pm 1.8$ & $7.1 \pm 1.5$ & $2.3 \pm 0.7$ & $3.1 \pm 0.4$ & 11.5 & * \\
\hline Trapped Insolubles (\%) & $9.7 \pm 0.8$ & $7.1 \pm 0.1$ & $6.4 \pm 1.5$ & $8.2 \pm 1.1$ & 7.52 & ns \\
\hline Bottom Insolubles (\%) & $8.3 \pm 0.5$ & $6.3 \pm 0.5$ & $5.7 \pm 0.5$ & $3.5 \pm 0.5$ & 4.74 & $*$ \\
\hline
\end{tabular}

colored complexes was then measured with a spectrophotometer, standard curves were generated for each nutrient species, and concentrations were calculated using the slope and $y$-intercept of these graphs. Sediment traps were used for estimating sedimentation (deposition) rates while suspended sediment (TSS) concentration and sedimentation rates were determined as described in [6]. Acid-insoluble fraction of sediment (noncarbonate fraction of terrestrial origin) was measured by digesting $5-10 \mathrm{~g}$ samples with $5 \%$ hydrochloric acid $[6,46]$.

2.3. Algal Abundance and Composition. Algal biomass and diversity were studied using 20-30 settlement tiles $(15 \mathrm{~cm} \times$ $15 \mathrm{~cm}$ ) deployed in each reef over a 120-day period [6] and thereafter transported to the laboratory in formalin. At the laboratory, tiles were first washed with fresh water to remove formalin and marine sediments, algae samples taken from each tile, and algal biomass determined by drying overnight in an oven at $80-100^{\circ} \mathrm{C}$. The remaining algae sample on tiles was used for algal identification microscopically to genus level and percent abundance of each taxon estimated using a square grid. At each of the reefs, algal cover on natural substrate was also studied by completing nine to twelve $10 \mathrm{~m}$ benthic transects loosely draped on the substrate for description of the bottom cover [47]. The length of transect $(>3 \mathrm{~cm})$ covered by turf, coralline, calcareous, and macroalgae was recorded.

2.4. Coral Recruitment and Diversity. Recruitment tiles were collected after 120 days, sediments were washed off, and tiles were sun-dried and then bleached to reveal coral recruits [6]. Coral recruits were examined microscopically at high magnification, counted, and identified to the family level following [48, 49]. Live corals on natural substrate were identified (to genus level) along nine $10 \mathrm{~m}$ transects at each reef site as described in [47] and were then compared to results of recruits on settlement tiles.

2.5. Data and Statistical Analysis. Physicochemical and biological data was log- and square-root-transformed, respectively, and normalized before analyses. One-way ANOVA was used for testing for differences in resultant data between reefs. Bartlett's and Shapiro-Wilk tests were used to test for homoscedasticity and normality of variance assumptions, respectively. Comparison between means was done using
Tukey's HSD where significant differences were detected in order to find out which means differed. The statistical programs JMP 7 and STATISTICA 6.0 for Windows were used for the above analyses. Multivariate analysis was used to explore the relationship between physicochemical and biological parameters using PRIMER and PERMANOVA. Resemblance matrices were calculated using Euclidean distances and patterns of similarity or differences were visualized using principal component analysis (PCA). PCA and a stepwise distance based linear model (DistLM) were employed to further explore significant correlations and facilitate data interpretation and also help in determining which factors (variables) captured as much of the variability of the response and differences between reefs in the dataset as possible.

\section{Results}

3.1. Physicochemical and Biological Parameters. Temperature, salinity, phosphates, and deposited (trapped) sediment acid insolubles did not differ between reefs but TSS and sediment deposition rates were found to be higher in Malindi and Watamu relative to the other study reefs (Table 1). Additionally, high bottom sediment acid-insoluble residue, current speed, and nitrate concentration were measured in Malindi but were found to be lower in Shimoni compared to the rest of the study reefs. Chlorophyll $a$ also differed significantly between reefs and was found to be lower in Mombasa and Shimoni but higher in Watamu and Malindi.

3.2. Algal Abundance and Composition. A total of thirty (30) species of algae belonging to thirteen (13) genera were observed on tiles in the present study (Table 2). The number of algae species identified from tiles in Malindi was found to be lower (twice or more) than that from the other reefs. Mean algal abundance did not exceed $5 \%$ or differ between reefs; however, mean algal biomass for Shimoni reef was higher than all other reefs studied (Figure 2). Turf algae dominated experimental tile surfaces with significant differences (Table 3, $F=26.3, p<0.0001$ ) between reefs (WTM $>$ MSA $>$ MLD $>$ SHM). Macro- and calcareous algae abundance did not differ between reefs but high coralline algae abundance was measured in Shimoni compared to all other reefs. 
TABLE 2: Algal species observed on experimental tiles and their presence $(+)$ or absence $(-)$ in four Kenyan protected coral reef lagoons.

\begin{tabular}{lcccc}
\hline Algae & Malindi & Watamu & Mombasa & Shimoni \\
\hline Acetabularia calyculus & + & - & - & - \\
Acetabularia clavata & + & - & + & - \\
Amphiroa sp. & - & - & + & + \\
Anadyomene wrightii & - & + & - & - \\
Boergesenia forbesii & - & + & + & - \\
Caulacanthus sp. & - & - & - & + \\
Caulerpa sp. & - & - & + & - \\
Ceramium sp. & - & + & - & + \\
Chnoospora implexa & - & - & - & + \\
Cladophora sp. & - & - & - & + \\
Cladophora socialis & + & - & - & + \\
Dictyota sp. & + & + & + & - \\
Enteromorpha sp. & + & - & + & + \\
Gracilaria sp. & - & + & + & + \\
Halimeda sp. & - & + & - & - \\
Herposphonia secunda & + & + & - & + \\
Jania & - & + & + & + \\
Lobophora sp. & - & - & - & + \\
Neomeris vanbosseae & - & + & - & - \\
Peyssonnelia sp. & - & + & + & + \\
Rosenvingea orientalis & - & - & + & - \\
Rosenvingea sp. & - & - & + & + \\
Sarconema sp. & + & + & - & - \\
Sargassum asperifolium & - & + & + & - \\
Sphacelaria sp. & - & + & + & + \\
Turbinaria sp. & - & + & + & - \\
Udotea sp. & - & - & + & - \\
Ulva lactuca & - & - & + & - \\
Unidentified green algae & - & - & + & - \\
Unidentified red algae & - & + & + & + \\
Number of species & 7 & 15 & 18 & 14 \\
\hline & & & & \\
\hline
\end{tabular}

Abundance of green (Chlorophyta) and red (Rhodophyta) algae showed no difference between reefs unlike that of brown algae (Phaeophyta), which was found to be high in Malindi and Mombasa compared to the rest of the study reefs (Table 3, $F=18.7, p<0.0001$ ). High turf algal cover on natural substrate was found in Mombasa and Watamu relative to the other reefs. Mombasa reef showed the lowest calcareous (0.1\%) and coralline (4.8\%) algae cover on natural substrate while high calcareous (16.3\%) and coralline (27.6\%) algae cover was measured in Malindi and Shimoni, respectively. Macroalgae abundance on natural substrate showed a general decline northward towards Malindi.

3.3. Recruit Density and Composition. Coral recruit density did not exceed 10 recruits per tile and did not differ between Watamu, Mombasa, and Malindi but was high in Shimoni compared to the other reefs (Figure 3). Overall, Acroporidae, Pocilloporidae, and Faviidae dominated recruit population



FIGURE 2: Total algal abundance (\%) on experimental tiles from four Kenyan protected reef coral lagoons (MLD: Malindi; WTM: Watamu; MSA: Mombasa; SHM: Shimoni).

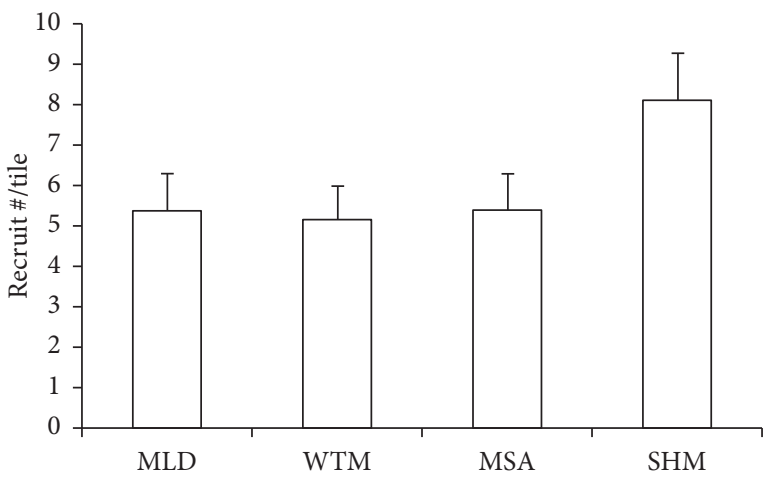

FIgURE 3: Coral recruit density (\#/tile) in four Kenyan protected reef lagoons (MLD: Malindi; WTM: Watamu; MSA: Mombasa; SHM: Shimoni).

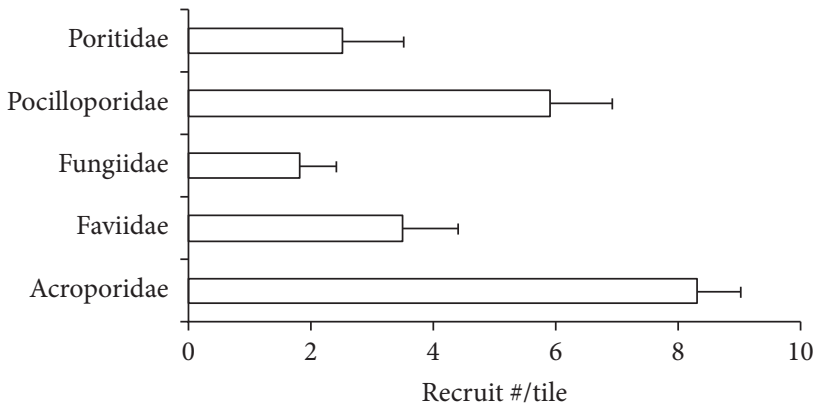

FIGURE 4: Composition of coral recruits (family) settling on experimental tiles deployed in Kenyan protected reef lagoons.

on individual tiles with Fungiidae recruits being the least common. Acroporidae, Pocilloporidae, and Faviidae dominated the recruit population in reefs $(F=8.1, p<0.001)$, with more acroporid recruits being observed in Shimoni compared to the other reefs (Figure 4 and Table 4). The density of Faviidae, Fungiidae, and Poritidae recruits did not differ between reefs; however, Pocilloporidae recruits were found to be dominant in Malindi and Mombasa reefs.

3.4. Sediment Level, Algae Abundance, and Coral Recruitment. Reefs affected by terrestrial discharge were found to have high 
TABLE 3: Percent algal abundance (type and phylum) on experimental tiles and natural substrates from four Kenyan protected coral reef lagoons including ANOVA test.

\begin{tabular}{lccccc}
\hline Algae & Malindi & Watamu & Mombasa & Shimoni & $p$ \\
\hline On tiles & & & & & \\
Turf & $20.0 \pm 4.1$ & $45.2 \pm 1.8$ & $31.9 \pm 4.1$ & $9.2 \pm 2.9$ & $*$ \\
Calcareous & $2.0 \pm 1.6$ & $0.7 \pm 1.8$ & $1.7 \pm 1.6$ & $0.5 \pm 1.5$ & $\mathrm{~ns}$ \\
Coralline & $3.9 \pm 4.1$ & 0 & 0 & $16.8 \pm 4.1$ & $*$ \\
Fleshy & $2.9 \pm 1.1$ & $2.0 \pm 1.1$ & $1.9 \pm 1.1$ & $1.0 \pm 1.1$ & $\mathrm{~ns}$ \\
\hline Chlorophyta & $0.9 \pm 1.4$ & $0.2 \pm 1.4$ & $0.6 \pm 1.4$ & $0.1 \pm 1.3$ & $\mathrm{~ns}$ \\
Phaeophyta & $5.7 \pm 1.8$ & $0.6 \pm 1.8$ & $3.0 \pm 1.5$ & $1.8 \pm 1.5$ & $*$ \\
Rhodophyta & $1.2 \pm 1.5$ & $3.6 \pm 1.4$ & $2.2 \pm 1.5$ & $2.7 \pm 1.4$ & $\mathrm{~ns}$ \\
\hline On natural & & & & & \\
substrate & & & & & \\
Turf & $25.3 \pm 10.0$ & $40.7 \pm 18.1$ & $34.2 \pm 4.4$ & $19.7 \pm 9.5$ & $*$ \\
Calcareous & $16.3 \pm 9.0$ & $12.1 \pm 10.2$ & $0.12 \pm 0.4$ & $13.5 \pm 6.4$ & $*$ \\
Coralline & $24.1 \pm 6.0$ & $23.9 \pm 12.0$ & $4.8 \pm 0.9$ & $27.6 \pm 2.9$ & $*$ \\
Fleshy & $9.2 \pm 6.0$ & $8.0 \pm 7.4$ & $4.3 \pm 6.7$ & $2.4 \pm 6.2$ & $*$ \\
\hline
\end{tabular}

total algal and Phaeophyta abundance on tiles but low recruit numbers, similar to the trend observed on natural substrate. High recruit density was also measured on tiles with low turf and high coralline algae abundance. However, contrary to expectations, reefs with high macroalgae abundance on tiles showed high recruit density as well. Calcareous algae abundance dynamics and effects on coral recruitment were not clear in the present study. The present observations also show that high turf, macro-, and Phaeophyta algae abundance on tiles and natural substrates were observed in reefs with high sediment levels unlike coralline and Rhodophyta algae. Chlorophyta abundance showed no significant changes with riverine influence. A correlation analysis of algal "types" showed that only total abundance of total and coralline algae had significant effects on coral recruit density (Table 5). These observations shed some light on the differential impact of terrestrial discharge on algae "types" and their subsequent influence on coral recruitment dynamics in coral reef lagoons. The present findings also suggest that the impact of sediment-nutrient interaction on algal turf differs from that of nutrient levels alone (see Watamu, Mombasa, and Malindi data). This is a key factor in the management and future of coral reefs adjacent to well developed coastal areas and those near river mouths with highly modified catchment areas.

3.5. Synthesis. Terrestrial influence (sediment deposition rates, bottom sediment organics, and nutrients), hydrodynamics (current speed), and seasonality (temperature and salinity variation) seem to be the dominant factors influencing the dynamics of biological processes in the current study. From the PCA analysis, the PC1 accounted for $61.3 \%$ of the total variation which strongly correlates with three of the original variables, increasing with increasing sediment deposition rates, ammonium, and temperature indicating a measure of sediment deposition rates and nutrient loading. PC2 explained $29.2 \%$ of the total variation, increasing
TABLE 4: Number of coral recruits (family) per tile in Kenyan protected reef lagoons (MLD: Malindi; WTM: Watamu; MSA: Mombasa; SHM: Shimoni).

\begin{tabular}{lccccc}
\hline Family/reef & MLD & WTM & MSA & SHM & $p$ \\
\hline Acroporidae & $7.3 \pm 1.6$ & $7.8 \pm 1.1$ & $7.3 \pm 1.4$ & $11.1 \pm 1.4$ & $*$ \\
Faviidae & $3.6 \pm 1.7$ & $3.0 \pm 2.7$ & $3.8 \pm 1.7$ & $3.8 \pm 2.9$ & $\mathrm{~ns}$ \\
Fungiidae & $2.0 \pm 5.1$ & $1.0 \pm 7.2$ & - & $2.0 \pm 7.2$ & $\mathrm{~ns}$ \\
Pocilloporidae & $7.0 \pm 2.1$ & $4.6 \pm 1.8$ & $6.7 \pm 2.3$ & $3.0 \pm 7.2$ & $*$ \\
Poritidae & $3.9 \pm 2.3$ & $1.6 \pm 2.4$ & $2.1 \pm 2.7$ & $2.0 \pm 2.9$ & $\mathrm{~ns}$ \\
\hline
\end{tabular}

TABLE 5: Correlation analysis between recruit density and algae types/forms from Kenyan protected lagoons, fitted to the model $y=a+b x$.

\begin{tabular}{lcccccc}
\hline & $n$ & $a$ & $b$ & $r$ & $r^{2}$ & $p$ \\
\hline All algae & 50 & 13.6 & -0.6 & 0.96 & 0.94 & $*$ \\
Turf algae & 17 & 74.1 & -7.9 & -0.71 & 0.50 & $\mathrm{~ns}$ \\
Calcareous algae & 25 & 3.5 & -0.4 & -0.70 & 0.49 & $\mathrm{~ns}$ \\
Coralline algae & 23 & -28.1 & +0.6 & 0.96 & 0.93 & $*$ \\
Macroalgae & 12 & 4.8 & -0.5 & -0.83 & 0.68 & $\mathrm{~ns}$ \\
\hline
\end{tabular}

with decreasing nitrate concentrations and current speeds, while the 3rd PC, a measure of bottom sediment organics, accounted for $8.0 \%$ of the total variations (Table 6). From the distance based linear model, sedimentation rate is indicated as the major factor affecting the biological data (algae and coral recruits). Plotting principal components reveals the importance of nutrients, sediment deposition, and hydrodynamics in the Malindi sediment impacted reef, for example (Figure 5). The highest loading coefficients in PC1 relate to sediment variables and those in PC3 to sea conditions (hydrodynamics), and in PC2 the highest loading coefficient relates to sea water chemistry (nutrients). Site hydrodynamics moderate sediment impacts and sediments in turn regulate (inhibit) the growth of algae possibly explaining the improved coral recruitment and settlement on the Malindi reefs. This interaction of the independent effects is captured in the PCA by the lowered loading coefficients. Thus, the principal components represent independent effects of the sum of interactions among sediment, nutrient, and reef hydrodynamics.

\section{Discussion}

Larval settlement and recruitment of new individuals is a key demographic process necessary for growth and maintenance, existence, and persistence as well as recovery and resilience of reef populations. However, optimum coral settlement and survival can only occur under certain physicochemical and biological conditions [50-52]; otherwise, coral mortality and algal colonization and dominance are enhanced while coral reestablishment is diminished. In the present study, diminished coral recruitment was observed in reefs close to nutrient sources (creeks) relative to those reefs impacted by river discharge, similar to other findings (see [53] and the references therein). This may possibly be attributed to increased nutrient levels enhancing algal growth and biomass 
TABLE 6: Principal component analysis (PCA): summary of environmental measurements and statistics and PCA results. Percent variance and eigenvalues explained for the first three components and environmental axis representing each.

\begin{tabular}{|c|c|c|c|}
\hline \multicolumn{4}{|c|}{ Multivariate analysis } \\
\hline Principal components & $P C 1$ & PC2 & PC3 \\
\hline Eigenvalue & 6.85 & 3.22 & 0.92 \\
\hline$\%$ variance explained & 61.3 & 29.2 & 8.0 \\
\hline Cumulative variance explained & 61.3 & 90.5 & 98.5 \\
\hline Variable & \multicolumn{3}{|c|}{ Component loadings } \\
\hline Sedimentation rate & 0.369 & -0.146 & -0.034 \\
\hline Temperature & 0.135 & -0.375 & 0.679 \\
\hline Current speed & 0.302 & 0.280 & 0.360 \\
\hline Bottom sediment organics & -0.356 & 0.087 & 0.339 \\
\hline Ammonium & 0.345 & -0.187 & -0.279 \\
\hline Nitrates & -0.097 & -0.523 & -0.244 \\
\hline
\end{tabular}

Distance based linear model; resemblance: S17 Bray-Curtis similarity

Sequential tests

$\begin{array}{lllllll}\text { Variable } & \text { AICc } & \text { df } & \text { SS (trace) } & \text { Pseudo-F } & p & \text { Prop. }\end{array}$

\begin{tabular}{lllllll} 
Sedimentation & 267.02 & 44 & 1566.4 & 4.9552 & 0.01 & 0.10122 \\
\hline
\end{tabular}

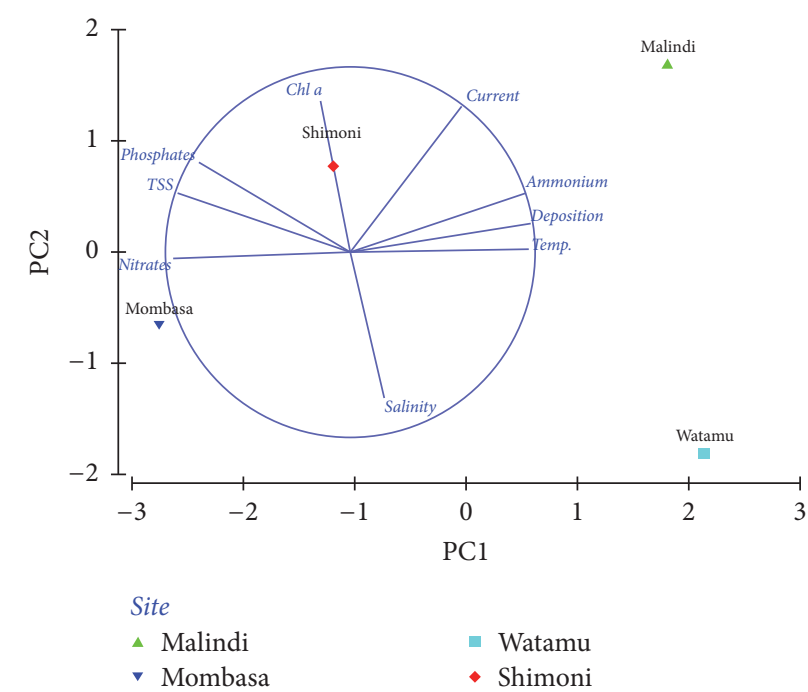

FIGURE 5: Principal component analysis plot of component 1 versus component 2. Temp.: temperature; TSS: total suspended sediments; Chl $a$ : chlorophyll $a$.

in which case algae outcompete coral recruits for available substrate for settlement $[21,32,39,41,44]$. In fact, $[7,54]$ found increased turf but reduced crustose coralline algal (CCA) growth under increased nutrient levels. Previous studies have shown that turf algae inhibit whereas CCA enhance coral settlement and recruitment $[53,54]$, possibly explaining the low and high densities of coral recruits in near and offshore reefs, respectively, in the present study. The slight improvement in recruit density observed in the river (nutrients and sediments) impacted Malindi reef suggests a reduction in the impact of algal growth by a counteracting effect of high sediment levels. Despite the well known direct negative effects of sediment on coral recruitment, increased sediment levels in coral reefs have been found to reduce the growth of algae $[16,45,55]$ and therefore mitigate the negative effects of algae on recruit density. This is similar to previous findings $[4,6,8,17,33]$ where reduced algal abundance but improved coral recruitment and settlement were reported in reefs with increased terrestrial influence.

The compromised capacity of corals to replenish via natural regeneration and larval settlement in reefs under terrestrially derived disturbances has been linked to the (1) masking of larval settlement cues, (2) interference with coral reproductive processes, and (3) interaction between coral larvae and settlement surfaces [54, 56, 57]. For instance, although algal communities are an integral part of coral reef ecosystems, in certain conditions, their presence has been shown to cause up to $75 \%$ reductions in coral recruitment $[15,44]$. Our study results are similar to previous findings [52, 57-59] where terrestrial discharge was reported to indirectly affect coral recruitment. The mechanisms involved are believed to include suppression of CCA growth, enhancement of turf and macroalgal proliferation [28], accumulation of sediments in algal turf as well as competition [8], and increased bleaching and tissue abrasion [60]. Moreover, increased sediments and nutrients levels have also been reported to influence the trajectory of algal succession [17, $45,56]$ with consequences on coral recruit composition. In the present study, brown algae (Phaeophyta) and pocilloporid coral recruits were dominant in reefs affected by terrestrial run-off explaining the high recruit numbers but low diversity in these reefs.

Land-based sources of pollution have been implicated in reduced coral reproduction including lowered fecundity and fertilization $[19,32]$ and subsequent low coral settlement and recruitment rates. For example, [50] found diminished egg size and fertilization rates, egg and embryo development, and spat density and survival as well as metamorphosis [61], in addition to low egg-sperm interactions, increased occurrence of irregular embryos, and failed planulation $[53,61]$ in the presence of high nutrient levels. All reefs with increased 
nutrient levels in the present study showed low coral recruit densities, possibly indicating the negative impact of nutrient on coral reproductive capacity and recruitment. Furthermore, the interference of sediments with coral spawning, sperm entry into eggs, embryogenesis, and larval development $[53,62]$ has also been implicated in controlling coral recruitment success. Moreover, elevated sediment levels also increase settlement on exposed surfaces or in cryptic habitats where survival and growth are highly compromised [53].

The present recruit density findings from Malindi reef were rather unexpected. Low coral recruit density has been observed in sediment impacted reefs as a result of energy utilization towards sediment removal, production of secondary metabolites such as mucus, and reduced energy allocation towards reproduction $[4,12,53,63]$. Despite that, coral recruit density in Malindi was found to be similar to that measured in Watamu and Mombasa. We postulate that improved coral recruit density measured in Malindi reefs resulted from the interactive effect of sediments and nutrients on algae. Whereas nutrients indirectly reduce coral settlement by promoting algal growth, sediments on the other hand have been reported to inhibit algal settlement, thus countering the negative effects of nutrients on coral recruitment, therefore enhancing coral settlement and recruitment $[4,8,12,15,44]$. Additionally, the hydrodynamic characteristics of Malindi reef may also have played a vital role in improving coral recruitment (see [34]). The presence of swift currents and moderate wave action and the presence of a deep-water channel possibly increased flushing rates, thus reducing sediment accumulation, but enhanced larval settlement [6] in Malindi reef.

The foregoing results suggest that the interaction of multiple environmental factors poses unique, complex, and interesting aspects of recruitment dynamics. For example, two distinct scenarios emerge from sediment-algal interaction on coral recruitment: (i) algae accumulate sediments, potentially increasing turbidity and recruit smothering, and reduce suitable substrate availability and cover of beneficial coralline algae $[64,65]$, leading to low coral settlement and recruitment rates, and (ii) sediments negatively affect algal growth, reproduction, and recruitment processes, thus offering corals a competitive advantage leading to increased coral settlement and recruitment $[30,55]$. However, these scenarios likely occur in the presence of other stressful environmental factors such as SST (bleaching), hydrodynamic energy, ocean acidification, diseases, and exploitative pressure. This dichotomy in sediment-algal interaction and its impact on coral recruitment may therefore evolve into a multiplex relationship with variable outcomes suggesting further investigations to determine under which specific environmental conditions and at what levels the above outcomes will be realized.

Sediments and algae therefore have significant effects on key life history stages of reef corals and are therefore critical in the resilience and recovery of disturbed reefs. Reefs with low recruitment rates will have their recovery rates severely impaired, more so where local and global factors interact to increase algal abundance, unsuitability of substrate, and the risk of damage to adult coral populations.
Generally, the four main components of terrestrial run-off (sedimentation, nutrients, organic matter, and turbidity) and their interactions have all been implicated in inhibiting coral pre- and postsettlement processes [53] and therefore their management is critically important in coral reef adaptability and resilience processes. This is especially vital since only minor benefits to coral reefs are predicted to be realized from current global climate change mitigation strategies $[66,67]$. It is also interesting to note that the percentages of insoluble sediments in our nearshore study reefs were lower than those found elsewhere $[14,68,69]$. Future studies in such reefs should also explore the role played by other components of terrestrially derived sediments (pollutants, organic content, and particle size characteristics) as well as carbonate sediments produced in situ as drivers of coral recruitment and algal dynamics.

Changes in local and global disturbance intensity and severity are expected to shift the competitive advantage in coral reefs towards algae dominance with concomitant modifications in coral pre- and postsettlement processes [70]. The capacity of such coral populations to reestablish will thus depend on habitat and population structure as well as the ability of few remaining individuals to supply larvae for settlement and growth in already unsuitable coral reef habitats. This is of great concern to the future health and existence of reefs worldwide, especially in reef areas already experiencing stress due to local anthropogenic factors. Current research undertakings should therefore focus on management and policy strategies that facilitate the alleviation and mitigation of the impacts of local anthropogenic disturbances guaranteed to produce results in the near future as opposed to long-term, often complex strategies employed to tackle global climate change.

\section{Conclusion}

The present findings suggest that the assessment of inhibitory and/or promotional factors in recruitment and settlement of corals is essential in reef recovery and resilience. Further, the study of environmental conditions that enhance and/or suppress these factors is therefore a critical aspect to consider in the conservation and management of coral reefs in the face of current and future disturbance dynamics. Therefore, the quantification of ecological processes and the factors that affect them may help in providing early evidence of reef resilience and, perhaps importantly, also allow for the development of models for forecasting ecosystem state of reefs.

\section{Conflicts of Interest}

The authors declare that there are no conflicts of interest regarding the publication of this paper.

\section{Acknowledgments}

Funding was provided by the International Development Research Centre (IDRC) Doctoral Research and Simon Fraser University (SFU) President's Awards, World Wildlife Fund (WWF), and British Ecological Society (BES) to the first 
author. Research authorization and logistics in marine parks were provided by the Kenya Wildlife Service (KWS). The authors are also thankful for the excellent fieldwork assistance provided by Masudi J. Zamu.

\section{References}

[1] B. S. Halpern, S. Walbridge, K. A. Selkoe et al., "A global map of human impact on marine ecosystems," Science, vol. 319, no. 5865, pp. 948-952, 2008.

[2] V. G. W. Schutte, E. R. Selig, and J. F. Bruno, "Regional spatiotemporal trends in Caribbean coral reef benthic communities," Marine Ecology Progress Series, vol. 402, pp. 115-122, 2010.

[3] H. Sweatman, S. Delean, and C. Syms, "Assessing loss of coral cover on Australia's Great Barrier Reef over two decades, with implications for longer-term trends," Coral Reefs, vol. 30, no. 2, pp. 521-531, 2011.

[4] K. L. Barott, G. J. Williams, M. J. A. Vermeij et al., "Natural history of coral-algae competition across a gradient of human activity in the Line Islands," Marine Ecology Progress Series, vol. 460, pp. 1-12, 2012.

[5] Y. Sawall, J. Jompa, M. Litaay, A. Maddusila, and C. Richter, "Coral recruitment and potential recovery of eutrophied and blast fishing impacted reefs in Spermonde Archipelago, Indonesia," Marine Pollution Bulletin, vol. 74, no. 1, pp. 374-382, 2013.

[6] S. A. Mwachireya, T. R. McClanahan, B. E. Hartwick, I. M. Cote, and L. Lesack, "Effects of river sediments on coral recruitment, algal abundance and benthic community structure on Kenyan coral reefs," African Journal of Environmental Science and Technology, vol. 9, no. 7, pp. 615-631, 2015.

[7] M. J. A. Vermeij, I. van Moorselaar, S. Engelhard, C. Hörnlein, S. M. Vonk, and P. M. Visser, "The effects of nutrient enrichment and herbivore abundance on the ability of turf algae to overgrow coral in the Caribbean," PLoS ONE, vol. 5, no. 12, Article ID e14312, 2010.

[8] G. Diaz-Pulido, M. Gouezo, B. Tilbrook, S. Dove, and K. R. N. Anthony, "High CO2 enhances the competitive strength of seaweeds over corals," Ecology Letters, vol. 14, no. 2, pp. 156-162, 2011.

[9] M. Carreiro-Silva and T. R. McClanahan, "Macrobioerosion of dead branching Porites, 4 and 6 years after coral mass mortality," Marine Ecology Progress Series, vol. 458, pp. 103-122, 2012.

[10] C. Reyes-Nivia, G. Diaz-Pulido, D. Kline, O.-H. Guldberg, and S. Dove, "Ocean acidification and warming scenarios increase microbioerosion of coral skeletons," Global Change Biology, vol. 19, no. 6, pp. 1919-1929, 2013.

[11] N. J. Silbiger and M. J. Donahue, "Secondary calcification and dissolution respond differently to future ocean conditions," Biogeosciences, vol. 12, no. 2, pp. 567-578, 2015.

[12] C. H. R. Goatley, R. M. Bonaldo, R. J. Fox, and D. R. Bellwood, "Sediments and herbivory as sensitive indicators of coral reef degradation," Ecology and Society, vol. 21, no. 1, article no. 29, 2016.

[13] S. B. Tebbett, C. H. R. Goatley, and D. R. Bellwood, "Fine sediments suppress detritivory on coral reefs," Marine Pollution Bulletin, 2016.

[14] S. B. Tebbett, C. H. Goatley, and D. R. Bellwood, "Algal turf sediments and sediment production by parrotfishes across the continental shelf of the northern great barrier reef," PLOS ONE, vol. 12, no. 1, p. e0170854, 2017.
[15] C. L. Birrell, L. J. McCook, and B. L. Willis, "Effects of algal turfs and sediment on coral settlement," Marine Pollution Bulletin, vol. 51, no. 1-4, pp. 408-414, 2005.

[16] R. J. Clausing, C. Annunziata, G. Baker, C. Lee, S. J. Bittick, and P. Fong, "Effects of sediment depth on algal turf height are mediated by interactions with fish herbivory on a fringing reef," Marine Ecology Progress Series, vol. 517, pp. 121-129, 2014.

[17] T. R. McClanahan and D. Obura, "Sedimentation effects on shallow coral communities in Kenya," Journal of Experimental Marine Biology and Ecology, vol. 209, no. 1-2, pp. 103-122, 1997.

[18] E. N. Edinger, G. V. Limmon, J. Jompa, W. Widjatmoko, J. M. Heikoop, and M. J. Risk, "Normal coral growth rates on dying reefs: Are coral growth rates good indicators of reef health?" Marine Pollution Bulletin, vol. 40, no. 5, pp. 404-425, 2000.

[19] D. B. Rasher, A. S. Hoey, and M. E. Hay, "Consumer diversity interacts with prey defenses to drive ecosystem function," Ecology, vol. 94, no. 6, pp. 1347-1358, 2013.

[20] K. Fabricius, G. De'ath, L. McCook, E. Turak, and D. M. Williams, "Changes in algal, coral and fish assemblages along water quality gradients on the inshore Great Barrier Reef," Marine Pollution Bulletin, vol. 51, no. 1-4, pp. 384-398, 2005.

[21] D. E. Burkepile, J. E. Allgeier, A. A. Shantz et al., "Nutrient supply from fishes facilitates macroalgae and suppresses corals in a Caribbean coral reef ecosystem," Scientific Reports, vol. 3, article no. 1493, 2013.

[22] R. Jones, G. F. Ricardo, and A. P. Negri, "Effects of sediments on the reproductive cycle of corals," Marine Pollution Bulletin, vol. 100, no. 1, pp. 13-33, 2015.

[23] J. H. Connell, T. P. Hughes, C. C. Wallace, J. E. Tanner, K. E. Harms, and A. M. Kerr, "A long-term study of competition and diversity of corals," Ecological Monographs, vol. 74, no. 2, pp. 179-210, 2004.

[24] Y. Sawall, N. Phongsuwan, and C. Richter, "Coral recruitment and recovery after the 2004 Tsunami around the Phi Phi Islands (Krabi Province) and Phuket, Andaman Sea, Thailand," Helgoland Marine Research, vol. 64, no. 4, pp. 357-365, 2010.

[25] O. Hoegh-Guldberg, "Climate change, coral bleaching and the future of the world's coral reefs," Marine and Freshwater Research, vol. 50, no. 8, pp. 839-866, 1999.

[26] J. F. Bruno, E. R. Selig, K. S. Casey et al., "Thermal stress and coral cover as drivers of coral disease outbreaks," PLoS Biology, vol. 5, no. 6, pp. 1220-1227, 2007.

[27] T. P. Hughes, M. J. Rodrigues, D. R. Bellwood et al., "Phase Shifts, Herbivory, and the Resilience of Coral Reefs to Climate Change," Current Biology, vol. 17, no. 4, pp. 360-365, 2007.

[28] G. Diaz-Pulido and L. J. McCook, "Effects of live coral, epilithic algal communities and substrate type on algal recruitment," Coral Reefs, vol. 23, no. 2, pp. 225-233, 2004.

[29] D. B. Rasher, E. P. Stout, S. Engel, J. Kubanek, and M. E. Hay, "Macroalgal terpenes function as allelopathic agents against reef corals," Proceedings of the National Academy of Sciences of the United States of America, vol. 108, no. 43, pp. 17726-17731, 2011.

[30] K. A. Hovel and R. N. Lipcius, "Effects of competition and herbivory on interactions between a hard coral and a brown alga," Journal of Experimental Marine Biology and Ecology, vol. 271, no. 1, pp. 25-39, 2002.

[31] C. A. C. Ramos, R. K. P. de Kikuchi, F. D. Amaral, and J. E. Fauth, "A test of herbivory-mediated coral-algae interaction on a Brazilian reef during a bleaching event," Journal of Experimental Marine Biology and Ecology, vol. 456, pp. 1-7, 2014. 
[32] L. J. McCook, J. Jompa, and G. Diaz-Pulido, "Competition between corals and algae on coral reefs: A review of evidence and mechanisms," Coral Reefs, vol. 19, no. 4, pp. 400-417, 2001.

[33] J. C. Gowan, The effects of water flow and sedimentation on interactions between massive porites and algal turf, [M.S. thesis], California State University, Northridge, LA, Calif, USA, 2012.

[34] J. C. Gowan, J. S. Tootell, and R. C. Carpenter, "The effects of water flow and sedimentation on interactions between massive Porites and algal turf," Coral Reefs, vol. 33, no. 3, pp. 651-663, 2014.

[35] T.-L. Loh and J. R. Pawlik, "Chemical defenses and resource trade-offs structure sponge communities on Caribbean coral reefs," Proceedings of the National Academy of Sciences of the United States of America, vol. 111, no. 11, pp. 4151-4156, 2014.

[36] J. M. Casey, J. H. Choat, and S. R. Connolly, "Coupled dynamics of territorial damselfishes and juvenile corals on the reef crest," Coral Reefs, 2014.

[37] C. H. R. Goatley and D. R. Bellwood, "Ecological Consequences of Sediment on High-Energy Coral Reefs," PLoS ONE, vol. 8, no. 10, Article ID e77737, 2013.

[38] M. L. Trapon, M. S. Pratchett, A. S. Hoey, and A. H. Baird, "Influence of fish grazing and sedimentation on the early postsettlement survival of the tabular coral Acropora cytherea," Coral Reefs, vol. 32, no. 4, pp. 1051-1059, 2013.

[39] D. E. Venera-Ponton, G. Diaz-Pulido, L. J. McCook, and A. Rangel-Campo, "Macroalgae reduce growth of juvenile corals but protect them from parrotfish damage," Marine Ecology Progress Series, vol. 421, pp. 109-115, 2011.

[40] J. L. Harris, L. S. Lewis, and J. E. Smith, "Quantifying scales of spatial variability in algal turf assemblages on coral reefs," Marine Ecology Progress Series, vol. 532, pp. 41-57, 2015.

[41] L. M. Nzali, R. W. Johnstone, and Y. D. Mgaya, "Factors affecting scleractinian coral recruitment on a nearshore reef in Tanzania," Ambio, vol. 27, no. 8, pp. 717-722, 1998.

[42] M. S. Thomsen and K. McGlathery, "Effects of accumulations of sediments and drift algae on recruitment of sessile organisms associated with oyster reefs," Journal of Experimental Marine Biology and Ecology, vol. 328, no. 1, pp. 22-34, 2006.

[43] Purcell and W. Steven, "Association of epilithic algae with sediment distribution on a windward reef in the northern Great Barrier Reef, Australia," Bulletin of Marine Science, vol. 66, no. 1, pp. 199-214, 2000.

[44] S. N. Arnold, R. S. Steneck, and P. J. Mumby, "Running the gauntlet: Inhibitory effects of algal turfs on the processes of coral recruitment," Marine Ecology Progress Series, vol. 414, pp. 91$105,2010$.

[45] S. K. Gorgula and S. D. Connell, "Expansive covers of turfforming algae on human-dominated coast: The relative effects of increasing nutrient and sediment loads," Marine Biology, vol. 145, no. 3, pp. 613-619, 2004.

[46] C. Bégin, C. K. Schelten, M. M. Nugues, J. Hawkins, C. Roberts, and I. M. Côté, "Effects of Protection and Sediment Stress on Coral Reefs in Saint Lucia," PLoS ONE, vol. 11, no. 2, Article ID e0146855, 2016.

[47] T. R. McClanahan and S. H. Shafir, "Causes and consequences of sea urchin abundance and diversity in Kenyan coral reef lagoons," Oecologia, vol. 83, no. 3, pp. 362-370, 1990.

[48] P. W. Sammarco, "Geographically specific recruitment and postsettlement mortality as influences on coral communities: The cross-continental shelf transplant experiment," Limnology and Oceanography, vol. 36, no. 3, pp. 496-514, 1991.
[49] R. C. Babcock, A. H. Baird, S. Piromvaragorn, D. P. Thomson, and B. L. Willis, "Identification of scleractinian coral recruits from Indo-Pacific reefs," Zoological Studies-Taipei, vol. 42, no. 1, pp. 211-226, 2003.

[50] C. Tran and M. G. Hadfield, "Larvae of Pocillopora damicornis (Anthozoa) settle and metamorphose in response to surfacebiofilm bacteria," Marine Ecology Progress Series, vol. 433, pp. 85-96, 2011.

[51] G. Suzuki and T. Hayashibara, "Do epibenthic algae induce species-specific settlement of coral larvaé," Journal of the Marine Biological Association of the United Kingdom, vol. 91, no. 3, pp. 677-683, 2011.

[52] J. Tebben, C. A. Motti, N. Siboni et al., "Chemical mediation of coral larval settlement by crustose coralline algae," Scientific Reports, vol. 5, Article ID 10803, 2015.

[53] K. E. Fabricius, "Effects of terrestrial runoff on the ecology of corals and coral reefs: Review and synthesis," Marine Pollution Bulletin, vol. 50, no. 2, pp. 125-146, 2005.

[54] S. A. Belliveau and V. J. Paul, "Effects of herbivory and nutrients on the early colonization of crustose coralline and fleshy algae," Marine Ecology Progress Series, vol. 232, pp. 105-114, 2002.

[55] M. J. Umar, L. J. McCook, and I. R. Price, "Effects of sediment deposition on the seaweed Sargassum on a fringing coral reef," Coral Reefs, vol. 17, no. 2, pp. 169-177, 1998.

[56] R. Albright and C. Langdon, "Ocean acidification impacts multiple early life history processes of the Caribbean coral Porites astreoides," Global Change Biology, vol. 17, no. 7, pp. 2478-2487, 2011.

[57] B. Schaffelke, "Short-term nutrient pulses as tools to assess responses of coral reef macroalgae to enhanced nutrient availability," Marine Ecology Progress Series, vol. 182, pp. 305-310, 1999.

[58] L. Penin, F. Michonneau, A. Carroll, and M. Adjeroud, "Effects of predators and grazers exclusion on early post-settlement coral mortality," Hydrobiologia, vol. 663, no. 1, pp. 259-264, 2011.

[59] S. Whalan, N. S. Webster, and A. P. Negri, "Crustose coralline algae and a cnidarian neuropeptide trigger larval settlement in two coral reef sponges," PLoS ONE, vol. 7, no. 1, Article ID e30386, 2012.

[60] J. Wiedenmann, C. D’Angelo, E. G. Smith et al., "Nutrient enrichment can increase the susceptibility of reef corals to bleaching," Nature Climate Change, vol. 3, no. 2, pp. 160-164, 2013.

[61] C. Humphrey, M. Weber, C. Lott, T. Cooper, and K. Fabricius, "Effects of suspended sediments, dissolved inorganic nutrients and salinity on fertilisation and embryo development in the coral Acropora millepora (Ehrenberg, 1834)," Coral Reefs, vol. 27, no. 4, pp. 837-850, 2008.

[62] D. F. Gleason and D. K. Hofmann, "Coral larvae: From gametes to recruits," Journal of Experimental Marine Biology and Ecology, vol. 408, no. 1-2, pp. 42-57, 2011.

[63] S. Harii, M. Yamamoto, and O. Hoegh-Guldberg, "The relative contribution of dinoflagellate photosynthesis and stored lipids to the survivorship of symbiotic larvae of the reef-building corals," Marine Biology, vol. 157, no. 6, pp. 1215-1224, 2010.

[64] P. T. Raimondi and A. N. C. Morse, "The consequences of complex larval behavior in a coral," Ecology, vol. 81, no. 11, pp. 3193-3211, 2000.

[65] L. Harrington, K. Fabricius, G. De'Ath, and A. Negri, "Recognition and selection of settlement substrata determine postsettlement survival in corals," Ecology, vol. 85, no. 12, pp. 34283437, 2004. 
[66] S. D. Donner, W. J. Skirving, C. M. Little, M. Oppenheimer, and O. Hoegh-Gulberg, "Global assessment of coral bleaching and required rates of adaptation under climate change," Global Change Biology, vol. 11, no. 12, pp. 2251-2265, 2005.

[67] J. C. Ortiz, Y.-M. Bozec, N. H. Wolff, C. Doropoulos, and P. J. Mumby, "Global disparity in the ecological benefits of reducing carbon emissions for coral reefs," Nature Climate Change, vol. 4, no. 12, pp. 1090-1094, 2014.

[68] K. Fabricius and G. De'ath, "Environmental factors associated with the spatial distribution of crustose coralline algae on the Great Barrier Reef," Coral Reefs, vol. 19, no. 4, pp. 303-309, 2001.

[69] S. E. Gordon, C. H. R. Goatley, and D. R. Bellwood, "Lowquality sediments deter grazing by the parrotfish Scarus rivulatus on inner-shelf reefs," Coral Reefs, vol. 35, no. 1, pp. 285-291, 2016.

[70] T. P. Hughes, A. H. Baird, D. R. Bellwood et al., "Climate change, human impacts, and the resilience of coral reefs," Science, vol. 301, no. 5635, pp. 929-933, 2003. 

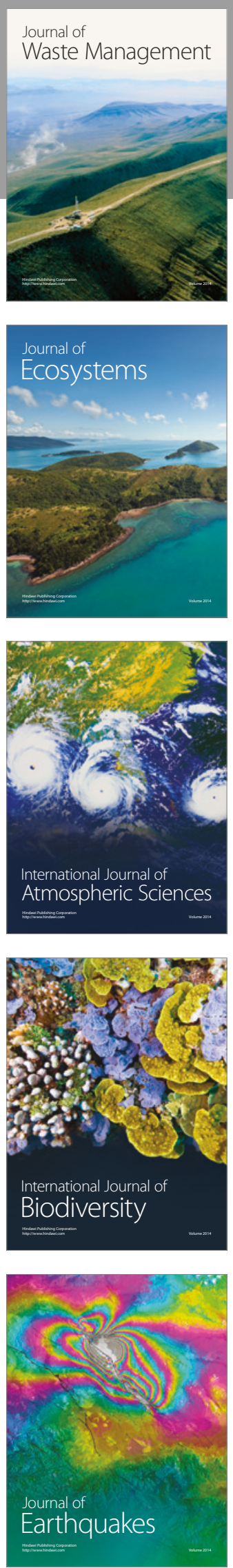
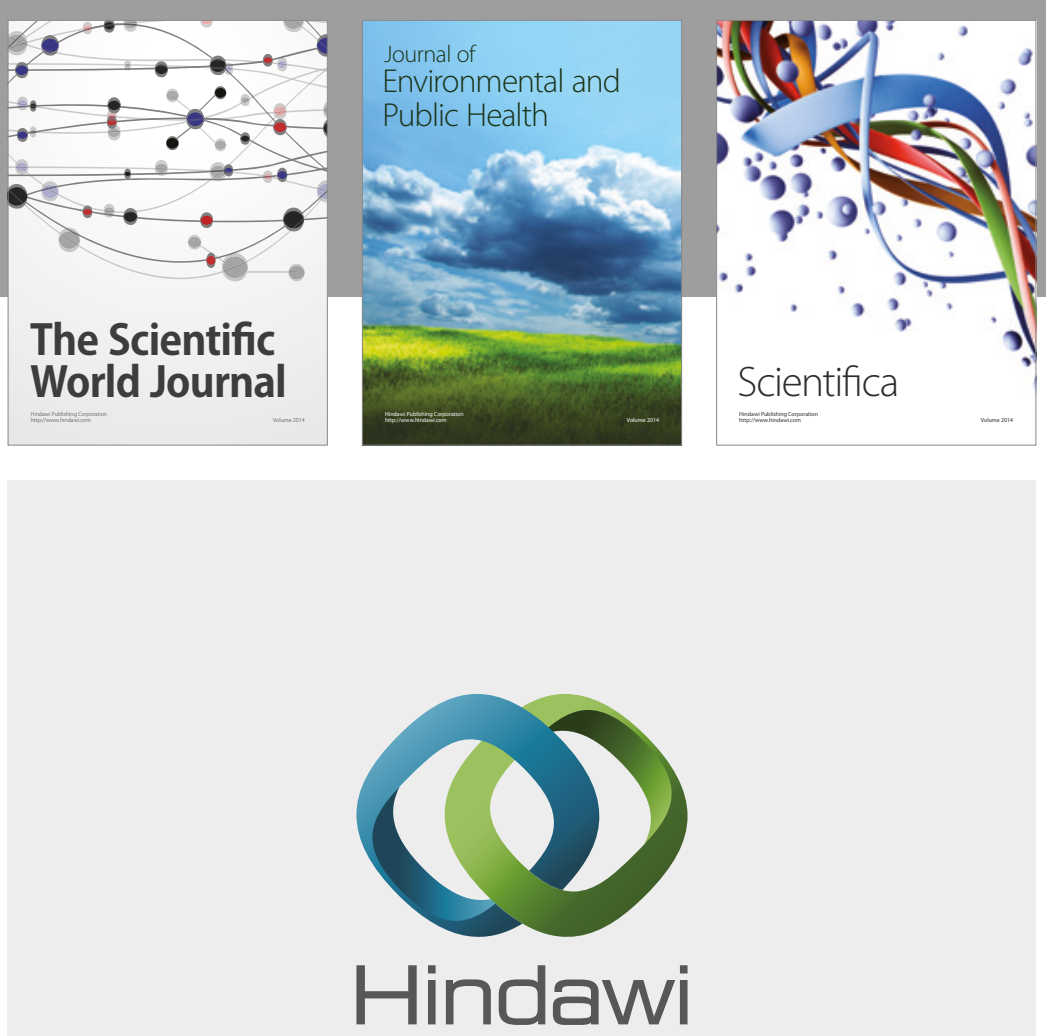

Submit your manuscripts at

https://www.hindawi.com
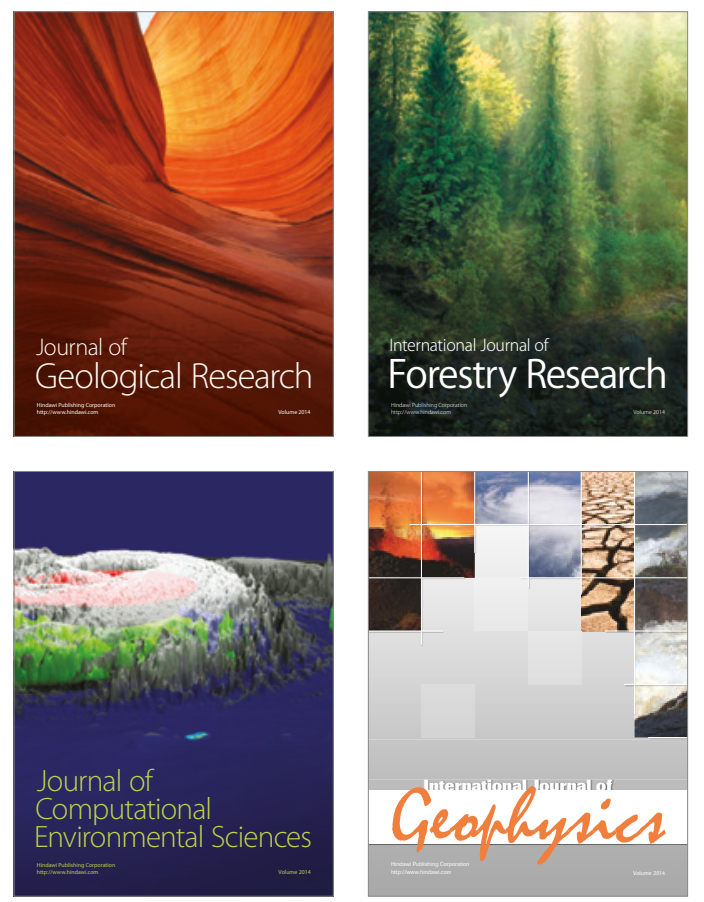
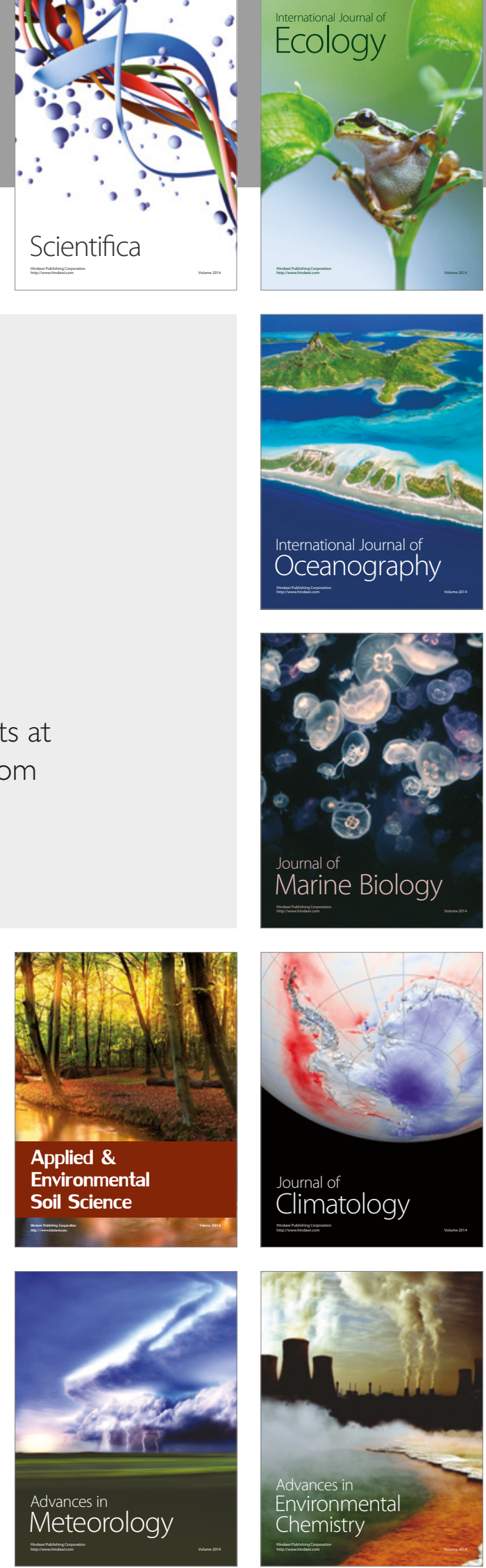